\title{
Lazer na America Latina/Tiempo libre, ocio y recreación en Latinoamérica
}

\section{Christianne Gomes, Esperanza Osorio, Leila Pinto, Rodrigo Elizalde (organizadores)}

\author{
Editora UFMG, Belo Horizonte, 2009, 398 págs.
}

\section{Antonio Elizalde Hevia*}

Recibido: 25.02.2010

Aceptado: 17.03.2010

Este libro registra, sistematiza, difunde y amplía el intercambio de experiencias sobre el tiempo libre, el ocio y la recreación, en América Latina. Ha sido elaborado en Brasil en colaboración con Colombia y Chile, países donde diversas personas e instituciones actuales aúnan esfuerzos en el sentido de fomentar los diálogos, incentivar estudios, compartir conocimientos y prácticas socioculturales sobre el tiempo libre, el ocio y la recreación en el contexto latinoamericano.

Presenta la realidad del tiempo libre, el ocio y la recreación en varios países latinoamericanos, a partir de estudios que permiten comprender como el tiempo libre, el ocio y la recreación fueron y son construidos social, política e históricamente en los países que integran América Latina, y asimismo entender como son vividos en la cotidianidad y han sido tratados por estudiosos y profesionales interesados en el tema. De ese modo hace posible iniciar una reflexión sobre el papel desempeñado por el tiempo libre, el ocio y la recreación en cada sociedad, sobre los obstáculos enfrentados, las posibilidades futuras y los desafíos superados.

Como lo señala en la contratapa del libro, Carlos Antonio Leite Brandão: "El ocio (sinónimo de lazer en portugués) configura los momentos en que atendemos a nuestras demandas internas y comunes, momento en que reconocemos y desarrollamos nuestras potencialidades, aprendemos el placer de brincar, de inventar, de imaginar y, sobre todo, de compartir con los otros las alegrías, las tristezas y los juegos con los cuales conquistamos lo mejor de nosotros mismos... Se rescata en esta obra el valor del ocio como resistencia en la construcción de nuestra identidad frente a una sociedad de masas y de consumo alienado donde la vivencia del otium y del licere es cada día más escasa y más necesaria. El ocio, el tiempo libre y la recreación no son puro mercado, interés ciego y negocio. Al definir el

*Universidad Bolivariana, Santiago, Chile. Email: aelizalde@ubolivariana.cl 
ocio como práctica social compleja y posibilidad de resistencia renace el sujeto, ciudadano y persona, al comprometerse con la creación de nuevas formas de organización social, histórica y espacial”.

Esta obra pionera trata de una temática actual que tendrá una creciente importancia en los años venideros: el ocio, el tiempo libre y la recreación en América Latina. Rescata las diversidades históricas, políticas y culturales de Argentina, Brasil, Chile, Colombia, Cuba, México, Uruguay y Venezuela desde distintas miradas. Los autores nos muestran las variadas perspectivas, presentando un rico material para fomentar el debate, las reflexiones críticas y la búsqueda de nuevos conocimientos que ayuden en la construcción de un mundo más humano, solidario y feliz.

Al renombrar al otium como derecho y necesidad humana fundamental y al sistematizar y difundir las experiencias sobre el ocio en América Latina, este libro cumple con el papel esencial de demarcar el campo donde se esboza una integración solidaria, humana, autónoma y libre para los latinoamericanos.

Dieciséis autores pertenecientes a ocho países confirmaron su participación en este trabajo colectivo a partir de sus estudios en Argentina, Brasil, Chile, Colombia, Cuba, México, Uruguay y Venezuela. Cada apartado de este libro contiene uno o dos textos que abordan la realidad del tiempo libre, el ocio y la recreación en cada uno de estos países. Cada investigador o grupo de investigadores responsables por el estudio del tema en cada país contextualizó los datos encontrados retratando su realidad desde su propia mirada y sus posibilidades de profundización teóricometodológica. Los distintos autores eligieron perspectivas de análisis diversas para reflexionar sobre lo que hay en común en nuestros países, lo que existe de distinto y también las múltiples posibilidades de intercambios solidarios en relación al aprendizaje colectivo sobre el tiempo libre, el ocio y la recreación en cuanto campo de experiencias, estudios, formación e intervención.

Los organizadores de este libro se preguntan “¿Qué pueden revelarnos sobre el tiempo libre, el ocio y la recreación las experiencias construidas en cada uno de los ocho países latinoamericanos que integran este libro? ¿Qué pueden revelarnos sobre nuestras sociedades las experiencias de tiempo libre, ocio y recreación desarrolladas en esas realidades?”

Los textos presentados en este libro ayudan a pensar esas y otras cuestiones, algunas específicas de cada país y otras comunes a toda Latinoamérica. En su conjunto los textos reunidos revelan una valiosa diversidad de visiones y perspectivas. Controvertidas algunas y en muchos casos mostrando oposiciones e incluso contradicciones entre ellas. Hay asimismo niveles de profundidad, consistencia teórica y análisis críticos muy diferentes, algo que expresa una sincera búsqueda de un diálogo que se pretende sea crítico, creativo, constructivo, altruista e innovador. De ese modo, sin embargo se ha logrado reunir un material de gran valor para 
promover el debate, las reflexiones críticas y la búsqueda de nuevos conocimientos.

El texto de autoría de Silvana Suárez referente al tiempo libre, el ocio y la recreación en Argentina discute la recreación como una práctica social compleja que da la posibilidad de resistencia a los sistemas tradicionales de organización social, cuando está comprometida con la libertad y el desarrollo humano. Señala la importancia de construir una "praxis en recreación" a partir de las condiciones reales de existencia de los pueblos latinoamericanos, que brinden ciudadanos emancipados en el pensamiento y la acción, con responsabilidad civil y respeto a las diferencias, facilitando la construcción de sujetos activos y transformadores de su realidad.

El artículo sobre el tiempo libre, el ocio y la recreación en Brasil cuyas autoras son Christianne Gomes y Leila Pinto, escrito originalmente en portugués fue traducido al español para facilitar la comprensión a los lectores de los países de habla hispana, se presenta en este libro en ambas lenguas. Sus autoras articulan un estudio bibliográfico con datos recogidos junto a 31 especialistas brasileños, profesionales formados en diversas áreas del conocimiento y con experiencia en el campo del tiempo libre, el ocio y la recreación. Considerando las complejidades, contradicciones, diversidades y dinamismos presentes en su país, observan que los conocimientos producidos y difundidos sobre el lazer en Brasil también han despertado el interés de académicos, gestores, educadores y miembros de la comunidad, en tanto posibilidad de transformación social contenidas en las vivencias crítica y creativa del lazer con miras a la construcción de una sociedad más humana, digna, justa, inclusiva y lúdica.

El texto presentado por Andrés Ried, Roberto Leiva y Rodrigo Elizalde presenta la realidad del tiempo libre, el ocio y la recreación en Chile realizando un recorrido por la historia de Chile, país que recién empieza a desarrollar referentes teóricos propios en las temáticas del ocio y la recreación. Analizan los conceptos de ocio y recreación, vinculándolos a las perspectivas y realidades económicas, turísticas de espacio público, del currículo escolar y la educación, además del uso del tiempo libre. El texto plantea interesantes preguntas así como propuestas innovadoras, tales cómo entender a la recreación como un potencial satisfactor sinérgico de la necesidad humana fundamental de ocio.

El texto que trata sobre Colombia de Esperanza Osorio revela los procesos de desarrollo de la recreación como campo de estudios y prácticas. La construcción de la recreación como campo y su posicionamiento es un resultado derivado de procesos políticos, académicos y de la emergencia de nuevos modos de abordar las prácticas, que han demandado una mejor y más compleja comprensión del fenómeno recreativo. Requiriendo cambios de paradigmas y un abordaje transdisciplinario que contribuyan a superar el lugar de subordinación que este campo de estudio ha ocupado en los modelos de desarrollo, las políticas y las instancias de producción de conocimientos. Destaca asimismo la contribución de la recreación para los 
procesos de transformación cultural, social y educativa en el país en tanto proyecto ético y político. Dicho texto presenta además un apartado de Maximiliano Quintero respecto a los programas de formación de postgrado.

El apartado referente a Cuba, de los autores Aldo Pérez y Santiago León, presenta un análisis del tiempo libre así como de las actividades realizadas en ese tiempo por la población de la isla, y constatan la existencia de una mayor disponibilidad de tiempo libre del hombre frente a la mujer. Los autores analizan los comportamientos de la población cubana ante las prácticas físico-deportivas y llegan a la conclusión que en la actualidad estas actividades no son frecuentes en los momentos de tiempo libre. Finalizan haciendo hincapié en la necesidad de una formación que valore nuevas competencias profesionales.

La recreación en México es de la autoría de Lupe Aguilar, quien resalta la influencia de la Asociación Cristiana de Jóvenes y de la Universidad Regional Miguel Hidalgo (URMH), entre otras instituciones, en el desarrollo de los programas de formación. Estas propuestas son vinculadas al área de la recreación en el país, en los niveles técnico profesional, pregrado y postgrado, y muchas veces solo enfatizan en el modelo norteamericano. Tras analizar una muestra de investigaciones desarrolladas sobre la recreación en la URMH, la autora en su conclusión ofrece una mirada interesante en torno a las tendencias teóricas sobre el tema en el contexto mexicano.

Ricardo Lema y Luís Machado presentan un texto sobre el tiempo libre y la recreación en Uruguay, nos cuentan como estas prácticas sociales llegaron a su país, señalan la influencia de los movimientos vinculados a la animación sociocultural y luego la educación popular, lo que sin lugar a dudas le dio a la recreación una dimensión más comunitaria. Destacan como la recreación se ha formalizado por la vía de la educación técnica y de la especialización universitaria, elemento decisivo para su desarrollo en el Uruguay.

Un segundo texto referido a Uruguay, de autoría de Fabián Vilas, contextualiza la recreación en su país y señala que en los años 80 se produce una explosión de experiencias de recreación. El autor indica que la recreación, desde una visión antropológica, es una producción social, un fenómeno que se origina y desarrolla en el marco de la cultura de un pueblo por lo cual es una realidad dinámica y en constante evolución. Concluye el texto planteado que el modelo de recreación uruguayo más allá de haberse cimentado teóricamente en los modelos externos, ha logrado desarrollar características propias.

Gladys Guerrero relata la historia de la recreación en Venezuela desde la creación del Consejo Venezolano del Niño en el año 1965. Este organismo desarrolló programas recreativos comunitarios y planes vacacionales dirigidos a la población infanto-juvenil de escasos recursos económicos. Señala como la recreación se incorporó al área de educación física obligatoria en todos los niveles y modalidades del sistema educativo venezolano, 
acompañando los postulados de la UNESCO para América Latina. Esta nueva orientación hizo que las instituciones formadoras de recursos humanos en Educación Física cambiaran su currículo, contemplando así la recreación como uno de los contenidos esenciales en el proceso formativo. Destaca que todavía sigue pendiente la aprobación de una Ley de Recreación para Venezuela, lo que se entiende como un elemento esencial para el ejercicio de la ciudadanía.

Un segundo artículo elaborado por Eloy Altuve trata sobre el ocio y la recreación en Venezuela desde los ámbitos político, administrativo, académico y de investigación. Su análisis presente los programas iniciados desde el año 1999 en el ámbito del Instituto Nacional de Deporte: Misión Barrio Adentro Deportivo (MBAD) y el Programa de Deporte Para Todos. Según el autor estos programas sobresalen por su carácter inclusivo y democrático con una clara intencionalidad de contribuir a la prevención y promoción de la salud, y ponen énfasis en las áreas de deporte recreativo, deporte competitivo y educación física. El autor señala la necesidad de generar procesos de reflexión y de construcción permanente y continua, sobretodo en lo referido a la formación humana y a la investigación, lo que podrá brindar a la recreación un campo propio, singular y específico.

Este libro representa una iniciativa pionera y de fundamental importancia en la contemporaneidad, pues como señalan sus organizadores "estrechar los vínculos entre las naciones que integran América Latina es fundamental pues nuestros países tienen límites y potencialidades distintos a la realidad verificada en los otros continentes. Justamente por esta razón es necesario incentivar los intercambios de saberes y experiencias que ocurren en el contexto latinoamericano.” 